\title{
Paroxetine but not imipramine improved depression related outcomes in adolescents with DSM-IV major depression
}

Keller MB, Ryan ND, Strober M, et al. Efficacy of paroxetine in the treatment of adolescent major depression: a randomized, controlled trial.J Am Acad Child Adolesc Psychiatry 2001 Jul;40:762-72.

\section{QUESTION: In adolescents with major depression, is paroxetine or imipramine more effective than placebo for improving depression related outcomes?}

Design

Randomised (unclear allocation concealement*), blinded (patients, clinicians, outcome assessors and statisticians)*, placebo controlled trial with 8 weeks of follow up.

\section{Setting}

10 centres in the US and 2 in Canada.

\section{Patients}

275 adolescents (mean age 15 y, $62 \%$ girls) who were medically healthy with a current episode of DSM-IV major depression for $\geqslant 8$ weeks. Additional inclusion criteria were a total score of $\geqslant 12$ on the Hamilton Depression Rating Scale (HDRS), a score of $<60$ on the Children's Global Assessment Scale, and a score of $\geqslant 80$ on the Peabody Picture Vocabulary Test. Exclusion criteria included a current or lifetime $D S M-I V$ diagnosis of bipolar disorder, schizoaffective disorder, eating disorder, alcohol or substance use disorder, and organic brain disorder. $99 \%$ of patients were included in the analysis.

\section{Intervention}

Patients were allocated to 8 weeks of paroxetine $(n=93)$, imipramine $(n=95)$, or placebo $(n=87)$. The paroxetine group received $20 \mathrm{mg} /$ day in the morning for weeks 1-4. Optional dose increases to $30 \mathrm{mg}$ /day were allowed at week 5 , and to $40 \mathrm{mg} /$ day at weeks $6-8$ if deemed necessary. The imipramine group received $50 \mathrm{mg}$ /day, 100 $\mathrm{mg} /$ day, $150 \mathrm{mg} /$ day, and $200 \mathrm{mg}$ /day during weeks 1 , 2, 3 , and 4 , respectively. Thereafter, optional dose increases to $250 \mathrm{mg}$ /day during week 5 and to $300 \mathrm{mg}$ /day during weeks $6-8$ were made if deemed necessary.

\section{Main outcome measures}

Main outcome measures were response (HDRS score $\leqslant 8$ or $\geqslant 50 \%$ reduction in baseline HDRS score at the end of treatment) and change from baseline in HDRS total score. Secondary outcome measures included change in the depressed mood item of the HDRS and Clinical Global Impression (CGI) improvement scores of 1 (very much improved) or 2 (much improved).

M B Keller,

Department of

Psychiatry and Human

Behavior, Brown

University School of

Medicine, 345

Blackstone Boulevard,

Providence, RI 02906,

PSAxetine or imipramine v placebo for major depression in adolescents

\begin{tabular}{lllll}
$\begin{array}{l}\text { Outcomes at } 8 \\
\text { weeks }\end{array}$ & Comparison & Event rates & RBI (95\% Cl) & NNT (CI) \\
HDRS score $\leqslant 8$ & Paroxetine $v$ placebo & $63 \% v 46 \%$ & $38 \%(5$ to 83$)$ & 6 (3 to 38) \\
\hline & Imipramine $v$ placebo & $50 \% v 46 \%$ & $48)$ & Not significant \\
\hline CGI score of 1 or 2 & Paroxetine $v$ placebo & $66 \% v 48 \%$ & $36 \%(5$ to 78$)$ & 6 (4 to 38) \\
\hline & Imipramine $v$ placebo & $52 \% v 48 \%$ & $45)$ & Not significant \\
\hline
\end{tabular}

†HDRS=Hamilton Depression Rating Scale; $\mathrm{CGl}=$ Clinical Global Impression. Other abbreviations defined in glossary; $\mathrm{RBI}, \mathrm{NNT}$, and $\mathrm{Cl}$ calculated from data in article. depressed mood item was greater in the paroxetine group than the placebo group (change from baseline 2 $v 1.3, \mathrm{p}=0.02$ ). The imipramine group did not differ from the placebo group for any of the outcome measures considered.

\section{Conclusions}

In adolescents with major depression, paroxetine was more effective than placebo for improving depression related outcomes on the 17 item Hamilton Rating Scale for Depression and Clinical Global Impression improvement scores. Imipramine did not differ from placebo for any of the outcomes.

*See glossary.

\section{COMMENTARY}

Depression is increasingly recognised to be common in adolescence, and also to be associated with serious long term problems. ${ }^{1}$ There have been very few well conducted randomised trials on pharmacotherapy in adolescents with depression, but a previous meta-analysis suggested that tricyclic antidepressants were of only marginal benefit in children and adolescents with depression. ${ }^{2}$ There are very few placebo controlled trials of selective serotonin reuptake inhibitors in this group.

This well conducted randomised controlled trial by Keller et al is therefore timely. The main finding was that paroxetine treatment was associated with a higher response rate at 8 weeks than imipramine or placebo, and only paroxetine was significantly more effective than placebo. There was a large differential dropout rate, with many more participants dropping out of imipramine treatment, which may have been due to the steep dosage regime (the average dose attained was $>200 \mathrm{mg}$ ). Although the finding is statistically significant, the clinical significance is less conclusive. The effect sizes reported are relatively modest when compared with placebo controlled trials of antidepressants in adults, with a remission rate of $63 \%$ on active treatment but $46 \%$ on placebo. This high remission rate on placebo concords with the previous meta-analysis ${ }^{2}$, and suggests that mood disorders in this group includes patients who have a more transitory pattern. These relatively modest results should also be placed in the context of the larger effect size reported in a small trial of interpersonal psychotherapy for depression in adolescents, ${ }^{3}$ where remission on the treatment was $75 \%$ v $46 \%$ in the control condition. Given the potentially harmful long term effects of depression in adolescence, future research needs to look at longer term social, educational, and occupational outcomes.

Matthew Hotopf, PhD, MRCPsych Guy's King's and St Thomas'School of Medicine London, UK

1 Weissman MM, Wolk S, Goldstein RB, et al. Depressed adolescents grown up. JAMA 1999;281:1707-13.

2 Hazell P, O'Connell D, Heathcote D, et al. Tricyclic drugs for depression in children and adolescents. Cochrane Database Syst Rev 2000;(3):CD002317.

3 Mufson L, Weissman MM, Moreau D, et al. Efficacy of interpersonal psychotherapy for depressed adolescents. Arch Gen Psychiatry 1999;56:573-9. 